\title{
Composición y función salival en niños con labio con/sin paladar hendido no sindrómico
}

\author{
Salivary composition and function in children with non-syndromic cl \\ w/wo $p$
}

\section{Composição e função salivar em crianças com fissuras labiais e/ou palatinas não sindrômicas}

\author{
Beatriz Helena Gallego-Molina ${ }^{1 凶} \underline{\mathrm{ORCID}}$, Yuly Catalina González-Vélez ${ }^{1 凶} \underline{\mathrm{ORCID}}$, Mariana

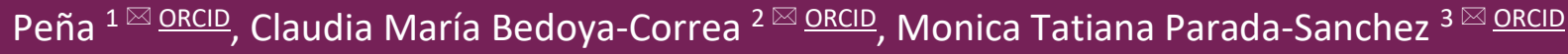 \\ ${ }^{1}$ Odontóloga, Facultad de Odontología, Universidad de Antioquia. \\ 2 Magister en Ciencias Odontológicas, Facultad de Odontología, Universidad de Antioquia. Grupo GIOM, Facultad de Odontología, \\ Universidad Cooperativa de Colombia-Campus Medellín. \\ ${ }^{3}$ Doctora en Biología Oral, Docente de la Facultad de Odontología, Departamento de Estudios Integrados, Grupo EBSC, Universidad \\ de Antioquia, Medellín, Colombia.
}

Fecha correspondencia:

Recibido: octubre de 2020.

Aprobado: septiembre de 2021.

Forma de citar:

Gallego-Molina BH, GonzálezVélez YC, Peña M, Bedoya-Correa CM, Parada-Sanchez MT. Composición y función salival en niños con labio con/sin paladar hendido no sindrómico. Rev.CES Odont 2022; 34 (2): 61-75.

https://doi.org/10.21615/

cesodon. 5923

Open access

(C) Derecho de autor

Licencia creative commons

Ética de publicaciones

Revisión por pares

Gestión por Open Journal System

DOI: 10.21615/cesodon.5923

ISSNe 2215-9185

ISSN 0120-971X

\section{Resumen}

Introducción y Objetivo: La saliva cumple una importante función en la homeostasis oral, aunque no es evaluada rutinariamente en pacientes con labio con/sin paladar hendido ( $\mathrm{LH} \pm \mathrm{PH})$. Este estudio pretendió comparar las características salivares de niños con $\mathrm{LH} \pm \mathrm{PH}$ no sindrómico vs. niños sin esta diferencia craneofacial. Materiales y métodos: Se incluyeron 17 niños con $\mathrm{LH} \pm \mathrm{PH}$ no sindrómico y 25 niños sin $\mathrm{LH} \pm \mathrm{PH}$, de los cuales se colectaron muestras de saliva estimulada (SE) y no estimulada (SNE). Se realizaron pruebas fisicoquímicas, cuantificación de iones ( $\mathrm{Ca}$, $\mathrm{Mg}$ y P), proteína total y recuento de streptococcus mutans en ambos grupos para ambas muestras de saliva. Para establecer comparaciones entre grupos se realizó la prueba no paramétrica de Mann-Whitney. Resultados: Hubo diferencias estadísticamente significativas en el $\mathrm{pH}$ de SE y SNE, así como en proteína total y capacidad amortiguadora de SNE. EI pH $(p=0,002)$ y capacidad amortiguadora $(p=0,023)$ de SNE de los niños con $\mathrm{LH} \pm \mathrm{PH}$ fueron menores, mientras que la concentración de 
proteína total $(p=0,003)$ fue mayor con respecto al grupo control. Se encontró mayor proporción de estreptococo mutans en SNE de niños con $\mathrm{LH} \pm \mathrm{PH}(6,39 \times 104 \mathrm{UFC} \mathrm{mL}-1)$ respecto al grupo control $\left(2,21 \times 10^{4}\right.$ UFC $\left.\mathrm{mL}^{-1}\right)$, aunque sin detectar diferencias estadísticamente significativas $(p=0,243)$. Conclusiones: Estos hallazgos sugieren una alteración en la función y composición de la SNE en pacientes con $\mathrm{LH} \pm \mathrm{PH}$ no sindrómico, que correspondería a una alteración en la formación y función de las glándulas salivales en estos individuos que requiere ser investigada.

Palabras clave: labio y/o paladar hendido; saliva; composición; función salival.

\section{Abstract}

Introduction and objective: Saliva plays an important role in oral homeostasis, although it is not routinely evaluated in patients with $C L \pm P$. This study aimed to compare these characteristics in children with non-syndromic $C L \pm P$ vs. children without this craniofacial difference. Materials and methods: This descriptive study included 17 children with nonsyndromic CL $\pm P$ from Fundación Clínica Noel and 25 children without $C L \pm P$. Stimulated (SS) and non-stimulated saliva (NSS) from both groups were collected for physicochemical tests, quantification of ions ( $\mathrm{Ca}, \mathrm{Mg}$ and $\mathrm{P}$ ), total protein and streptococcus mutans count. Results: There were statistically significant differences in $\mathrm{pH}$ of SS and NSS, as well as in total protein concentration and buffer capacity in NSS. The $\mathrm{pH}(\mathrm{p}=0.002)$ and buffering capacity $(p=0.023)$ of NSS of CLIP children decreased, while total protein concentration $(p=0.003)$ increased compared to the control group. A higher streptococcus mutans count was found in NSS of CL $\pm P$ children $\left(6.39 \times 10^{4} \mathrm{CFU}_{\text {UFC mL }}^{-1}\right)$ compared to the control group $\left(2.21 \times 10^{4} \mathrm{UFC} \mathrm{mL}^{-1}\right)$, although without detecting statistically significant differences $(p=0.243)$. Conclusions: These findings suggest an alteration in the function and composition of NSS in patients with non-syndromic $\mathrm{CL} \pm \mathrm{P}$; which could possibly be explained from the genetic/biological point of view by an alteration in the salivary glands formation and function in these individuals that requires further investigation.

Keywords: cleft lip with or without cleft palate; saliva; composition; salivary function.

\section{Resumo}

Introdução e objetivo: A saliva desempenha um papel fundamental na homeostase oral, não é avaliada rotineiramente em pacientes com FL/P. Portanto, este estudo objetivou indagar essas características em crianças com FL/P não sindrômico. Materiais e métodos: 17 crianças 
com FL/P não sindrômico da Fundación Clínica Noel, e 25 crianças sem FL/P foram incluídas neste estudo. Amostras de saliva estimulada (SE) e saliva não estimulada (SNE) foram coletadas para realização de testes físico-químicos, quantificação de íons ( $\mathrm{Ca}, \mathrm{Mg}$ e $\mathrm{P}$ ), proteína total e contagem de streptococcus mutans. Resultados: Houve diferenças estatisticamente significativas no $\mathrm{pH}$ de SE e SNE, bem como na concentração de proteína total e capacidade tampão de SNE. O pH $(p=0,002)$ e a capacidade tampão $(p=0,023)$ de SNE de crianças com FL/P foram menores, enquanto a concentração de proteína total $(p=0,003)$ foi maior, quando comparado ao grupo controle. Um contagem maior de streptococcus mutans foi encontrada na saliva não estimulada de crianças com $\mathrm{FL} / \mathrm{P}\left(6,39 \times 10^{4} \mathrm{UFC} \mathrm{mL}^{-1}\right)$ em comparação ao grupo controle $\left(2,21 \times 10^{4}\right.$ UFC $\left.\mathrm{mL}^{-1}\right)$, embora sem detectar diferenças estatisticamente significativas $(p=0,243)$. Conclusão: Esses achados sugerem uma alteração na função e composição da SNE em pacientes com FL/P não sindrômico; isso possivelmente poderia ser explicado do ponto de vista genético/biológico por uma alteração na formação e função das glândulas salivares nesses indivíduos que requer investigação.

Palavras-chave: fissura labial e/ou palatina; saliva; composição; função salivar.

\section{Introducción}

El labio con/sin paladar hendido $(\mathrm{LH} \pm \mathrm{PH})$ es una de las malformaciones craneofaciales congénitas más comunes a nivel mundial ${ }^{(1)}$. En Colombia, el Instituto Nacional de Salud reportó una prevalencia de 8,5 por 10.000 nacidos vivos en el $2017^{(2)}$. Esta malformación se presenta como resultado de la falta de fusión de las masas mesenquimatosas de las prominencias nasales y las maxilares que debería darse entre la sexta y séptima semana del desarrollo intrauterino, comprometiendo la formación de un labio superior, paladar primario y/o paladar secundario intactos ${ }^{(3,4)}$. $\mathrm{LH} \pm \mathrm{PH}$ se puede manifestar de forma sindrómica en el $30 \%$ de los casos, y no sindrómica (de manera aislada) en el otro $70 \%{ }^{(5)}$. En ambos tipos de LH $\pm \mathrm{PH}$, además de las repercusiones médicas que conlleva esta anomalía, se presentan grandes compromisos a nivel orofacial como incompatibilidad labial y del velo faríngeo, respiración oral, hipoplasias de esmalte, caries dental, gingivitis, periodontitis, entre otros ${ }^{(6)}$. Adicionalmente, se ha reportado que las personas con $\mathrm{LH} \pm \mathrm{PH}$ presentan mayor dificultad en la higiene oral afectando aún más su calidad de vida ${ }^{(7)}$. Aunque existen múltiples factores ambientales asociados con la etiología de $\mathrm{LH} \pm \mathrm{PH}$, el componente genético es uno de los aspectos de mayor contribución en su aparición. De hecho, se ha reportado que variaciones en la secuencia de múltiples genes son necesarias y predisponen a la presentación de esta malformación ${ }^{(1,8-10)}$. 
La saliva tiene funciones esenciales relacionadas con la protección, lubricación, aclaramiento y dilución de azúcares y ácidos, capacidad amortiguadora, remineralización dental y propiedades antimicrobianas ${ }^{(11-13)}$. Por lo tanto, alteraciones que afecten la función, composición y flujo salival pueden comprometer el equilibrio ecológico de la cavidad oral ${ }^{(14,15)}$. La disfunción salival es indicativa de la presencia de enfermedades sistémicas y orales; por esta razón, la saliva puede ser utilizada con fines diagnósticos, por lo que ha sido investigada como fuente de biomarcadores específicos para enfermedades humanas como cáncer, periodontitis e inclusive en $\mathrm{LH} \pm \mathrm{PH}{ }^{(16-18)}$. A pesar del importante papel que desempeña la saliva en la homeostasis oral, no es evaluada rutinariamente en la práctica clínica general y de pacientes con diferencias craneofaciales como el $\mathrm{LH} \pm \mathrm{PH}$. Las diferencias en las características bioquímicas salivares con relación a pacientes sanos podrían actuar como posibles factores contribuyentes a la perdida de la salud bucal en los pacientes con $\mathrm{LH} \pm \mathrm{PH}$ no sindrómicos. La presente investigación tiene como objetivo comparar la funcionalidad de las glándulas salivales (composición, tasa de secreción, pH, capacidad amortiguadora de la saliva, cantidad de células viables de streptococcus mutans) en niños con $\mathrm{LH} \pm \mathrm{PH}$ con la de niños $\sin \mathrm{LH} \pm \mathrm{PH}$.

\section{Materiales y métodos}

\section{Población de estudio}

Este estudio descriptivo transversal contó con una muestra de 42 niños entre los 5 a 10 años (17 niños con LH \pm PH no sindrómico de la Fundación Clínica Noel y 25 niños de grupo control sin LH $\pm \mathrm{PH}$ - de la ciudad de Medellín). Los niños incluidos en el estudio no presentaban compromiso sistémico, alteraciones del desarrollo dental ni aparatología ortodóntica, además, se excluyeron niños con alguna discapacidad que impidiera la recolección de las muestras, y niños que hubieran recibido terapia antibiótica o antimicótica 3 meses previos a la toma de la muestra. Los padres de familia y los menores recibieron información sobre los objetivos del estudio y firmaron un consentimiento y asentimiento informado. Este estudio fue aprobado por el Comité de Ética de la Facultad de Odontología de la Universidad de Antioquia (acta número 03/2017) y por el Comité de Ética de la Fundación Clínica Noel (23/02/2017).

\section{Recolección de muestras de saliva}

Para minimizar el efecto de los ritmos circadianos se colectaron de manera simultánea muestras de saliva no estimulada (SNE) y saliva estimulada (SE) una hora después del desayuno. Los niños suspendieron los enjuagues bucales al menos siete días previos a la toma de la muestra, realizaron cepillado de dientes en la mañana después del desayuno y no consumieron 
ningún alimento una hora antes del muestreo. Las muestras se almacenaron a $4^{\circ} \mathrm{C}$ en hielo y se procesaron dentro de las siguientes $2 \mathrm{~h}$.

\section{Análisis fisicoquímico de SNE y SE}

Se calculó la tasa secreción salival dividiendo el volumen de saliva colectado por el tiempo de estimulación de las glándulas salivales (5 min). Posteriormente, el pH de la saliva fue estimado mediante el uso de un pHmetro digital (HI 2221, HANNA Instruments, Colombia). Para determinar la capacidad amortiguadora de la saliva se realizó el método de Ericsson modificado ${ }^{(19)}$. Las muestras fueron alicuotadas por duplicado y centrifugadas a $8000 \mathrm{rpm}$ por

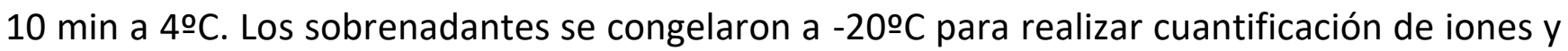
proteína total.

\section{Recuento de estreptococos del grupo mutans (EM)}

Se realizaron microdiluciones de las muestras de SNE y SE en solución salina 0,9\%. $100 \mu \mathrm{L}$ de las diluciones $10^{-1}-10^{-3}$ fueron inoculados en Agar Mitis Salivarius (Difco Laboratories, Le pont de claix, France) con telurito de potasio al 1\% (Lab M Ltd, Lancashire, UK), 10\% de sacarosa (Fisher Chemical, Waltham, USA) y 0,2 $\mathrm{U} \mathrm{mL}^{-1}$ de bacitracina (Sigma-Aldrich, Missouri, USA). Los cultivos fueron incubados a $37^{\circ} \mathrm{C}$ por $48 \mathrm{~h}$ en $5 \%$ de $\mathrm{CO}_{2}$. Posteriormente, se realizó el recuento de células viables el cual fue expresado como UFC mL-1 (Unidades Formadoras de Colonias por mililitro de saliva).

\section{Cuantificación de proteína total}

Se empleó el método de Bradford con el kit Bio-Rad Protein Assay (Sigma-Aldrich, Missouri, USA). Se realizó la curva de calibración con la proteína estándar albúmina de suero bovino-BSA. Posteriormente, para determinar la concentración de proteína, se mezclaron $10 \mu \mathrm{L}$ de cada una de las muestras de saliva con $200 \mu \mathrm{L}$ del colorante azul brillante Coomassie G-250. Las muestras fueron incubadas a temperatura ambiente por 5 min y se midió la absorbancia a una densidad óptica (DO) de $595 \mathrm{~nm}$.

\section{Cuantificación de iones de calcio}

Se utilizó el kit Calcium Colorimetric Assay (Sigma-Aldrich, Missouri, USA). Luego de realizar la curva de calibración a partir de una solución de calcio $5 \mathrm{mM}$, se realizó la cuantificación de iones de calcio. Se mezclaron $40 \mu \mathrm{L}$ de cada muestra con $10 \mu \mathrm{L}$ de agua ultrapura. Posteriormente, se agregó $90 \mu \mathrm{L}$ de reactivo cromogénico y $60 \mu \mathrm{L}$ de buffer de calcio. Las muestras fueron incubadas a temperatura ambiente por 10 min y se midió la absorbancia (D0575nm). 


\section{Cuantificación de fosfato}

El kit Phosphate Colorimetric Assay (Sigma-Aldrich, Missouri, USA) fue empleado para medir los niveles de fosfato. La curva de calibración se realizó a partir de una solución estándar fosfato de 0,1 mM. Antes de cuantificar los niveles de fosfato, la SNE y SE fue diluida en agua ultrapura (1:4). Posteriormente, $2 \mu \mathrm{L}$ de las muestras fueron mezcladas con $198 \mu \mathrm{L}$ de agua ultrapura y $30 \mu \mathrm{L}$ de reactivo fosfato. Las muestras fueron incubadas a temperatura ambiente por $30 \mathrm{~min}$ y se determinó la absorbancia (DO650 nm).

\section{Cuantificación de magnesio}

Se usó el kit Magnesium Assay (Sigma-Aldrich, Missouri, USA). La curva de calibración se realizó a partir de una solución estándar de magnesio. Posteriormente, para determinar la concentración de magnesio en las muestras, $10 \mu \mathrm{L}$ de SNE y SE fueron homogenizadas con 40 $\mu \mathrm{L}$ agua ultrapura. Seguidamente, se adicionó $50 \mu \mathrm{L}$ de la mezcla de reacción (Magnesium Assay Buffer, Magnesium Developer y Magnesium Enzyme Mix). La absorbancia fue medida (DO450 nm) luego incubar las muestras a $37^{\circ} \mathrm{C}$ por $10 \mathrm{~min}$.

\section{Análisis estadísticos}

Los análisis estadísticos se realizaron usando el programa SPSS versión 21. Las variables cuantitativas fueron descritas mediante el uso de medidas de tendencia central. Para contrastar la normalidad de los datos se realizó la prueba de Kolmogorov-Smirnov. Para realizar comparaciones entre grupos se realizó la prueba no paramétrica de Mann-Whitney. Los valores de $p<0,05$ fueron considerados significativos.

\section{Resultados}

\section{Descripción de la población de estudio}

El promedio de edad de los pacientes con $\mathrm{LH} \pm \mathrm{PH}$ fue de 8,71 años y del grupo control 8,40 años. El género masculino predominó en ambos grupos ( $\underline{\text { Tabla } 1}$ ). En el grupo $\mathrm{LH} \pm \mathrm{PH}$, la anomalía más común fue labio y paladar hendido unilateral izquierdo $(41,18 \%)$, seguida de labio y paladar hendido unilateral derecho $(35,29 \%)$, paladar hendido $(17,65 \%)$, y labio y paladar hendido bilateral (5,88\%). 
Tabla 1. Distribución de la muestra de estudio.

\begin{tabular}{lcc}
\hline Variable & Grupo $\mathbf{L H} \pm \mathbf{P H}(\boldsymbol{n = 1 7 )}$ & Grupo Control $(\boldsymbol{n}=\mathbf{2 5})$ \\
\hline Edad (Media $\pm \mathrm{DE})$ & $8,71 \pm 1,76$ & $8,40 \pm 1,63$ \\
\hline Género & & \\
\hline Femenino & $8(47,06 \%)$ & $7(28 \%)$ \\
\hline Masculino & $9(52,94 \%)$ & $18(72 \%)$ \\
\hline
\end{tabular}

\section{Análisis fisicoquímico de saliva estimulada y no estimulada}

En las tablas 2 y 3 se describen las características fisicoquímicas de SE y SNE de los grupos $\mathrm{LH} \pm \mathrm{PH}$ y control. Estas características fueron significativamente diferentes dentro de cada grupo al comparar SE frente a SNE (SE: mayores tasas de secreción salival, pH salival y capacidad amortiguadora) $(\mathrm{p}<0,05)$. A pesar que los valores de secreción y $\mathrm{pH}$ salival de los grupos $\mathrm{LH} \pm \mathrm{PH}$ y control fueron similares, la tasa de secreción salival de SE y SNE del grupo control mostró una tendencia a ser mayor. La capacidad amortiguadora de la saliva del grupo LH \pm PH fue más baja tanto en SE como en SNE, comparada con el grupo control (Tabla 2).

Tabla 2. Comparación de las características fisicoquímicas salivares según la presencia o ausencia de LH \pm PH en ambos tipos de saliva (SE y SNE).

\begin{tabular}{lcccccc}
\hline \multirow{2}{*}{ Variable } & \multicolumn{3}{c}{ LH \pm PH (Media $\pm D E)$} & \multicolumn{3}{c}{ Control (Media $\pm D E)$} \\
\cline { 2 - 6 } & SE & SNE & p-value & SE & SNE & -value \\
\hline $\begin{array}{l}\text { Tasa de secreción } \\
\text { salival (mL/min) }\end{array}$ & $1,03 \pm 0,55$ & $0,25 \pm 0,18$ & $\mathbf{0 , 0 0 0 *}$ & $1,20 \pm 0,61$ & $0,28 \pm 0,13$ & $\mathbf{0 , 0 0 0 *}$ \\
\hline $\mathrm{pH}$ salival & $7,78 \pm 0,24$ & $7,02 \pm 0,33$ & $\mathbf{0 , 0 0 0 *}$ & $8,13 \pm 0,28$ & $7,52 \pm 0,51$ & $\mathbf{0 , 0 0 0 *}$ \\
\hline $\begin{array}{l}\text { Capacidad } \\
\text { amortiguadora }\end{array}$ & $4,79 \pm 1,47$ & $3,48 \pm 0,64$ & $\mathbf{0 , 0 1 1 *}$ & $5,50 \pm 1,11$ & $4,09 \pm 1,06$ & $\mathbf{0 , 0 0 0 *}$ \\
\hline
\end{tabular}

${ }^{*} p<0,05$. Prueba de Mann-Whitney.

Al comparar las características fisicoquímicas de SE entre ambos grupos, los valores correspondientes a la tasa de secreción y capacidad amortiguadora no tuvieron diferencias estadísticamente significativas $(p>0,05)$. En comparación, sólo la capacidad amortiguadora de la SNE en el grupo $\mathrm{LH} \pm \mathrm{PH}$ fue estadísticamente menor en comparación con la del grupo control 
$(p=0.023)$. En cuanto al pH salival de SE y SNE de ambos grupos, fue posible establecer una disminución significativa en los valores de $\mathrm{pH}$ del grupo $\mathrm{LH} \pm \mathrm{PH}$ obtenidos en SE y SNE al compararlos con los valores control $(p<0,01)$ (Tabla 3 ).

Tabla 3. Comparación de las características fisicoquímicas salivares según el tipo de saliva (SE y SNE) en ambos grupos en estudio.

\begin{tabular}{lcccccc}
\hline \multirow{2}{*}{ Variable } & \multicolumn{3}{c}{ SE (Media $\pm D E)$} & \multicolumn{3}{c}{ SNE (Media $\pm D E)$} \\
\cline { 2 - 6 } & $\mathbf{L H} \pm \mathbf{P H}$ & Control & $\boldsymbol{p}$-value & LH $\pm \mathbf{P H}$ & Control & $\boldsymbol{p}$-value \\
\hline $\begin{array}{l}\text { Tasa de secreción } \\
\text { salival (ml/min) }\end{array}$ & $1,03 \pm 0,55$ & $1,20 \pm 0,61$ & 0,616 & $0,25 \pm 0,18$ & $0,28 \pm 0,13$ & 0,227 \\
\hline pH salival & $7,78 \pm 0,24$ & $8,13 \pm 0,28$ & $\mathbf{0 , 0 0 0 *}$ & $7,02 \pm 0,33$ & $7,52 \pm 0,51$ & $\mathbf{0 , 0 0 2 *}$ \\
\hline $\begin{array}{l}\text { Capacidad } \\
\text { amortiguadora }\end{array}$ & $4,79 \pm 1,47$ & $5,50 \pm 1,11$ & 0,124 & $3,48 \pm 0,64$ & $4,09 \pm 1,06$ & $\mathbf{0 , 0 2 3 *}$ \\
\hline
\end{tabular}

${ }^{*} p<0,05$. Prueba de Mann-Whitney.

\section{Recuento de estreptococos del grupo mutans (EM)}

Los niveles de EM fueron superiores en SE en ambos grupos, en comparación con lo observado en SNE. A pesar de no encontrar diferencias estadísticamente significativas en los recuentos en SE y SNE en los grupos evaluados, se evidencia un notable incremento en los recuentos de EM de SNE en el grupo LH \pm PH (Tabla 4).

Tabla 4. Recuento de células viables de EM en SE y SNE de niños $L H \pm P H$ y control.

\begin{tabular}{|c|c|c|c|c|c|}
\hline \multicolumn{2}{|c|}{ UFC $\mathrm{mL}^{-1}$ en SE (Media $\left.\pm D E\right)$} & \multicolumn{4}{|c|}{ UFC $m L^{-1}$ en SNE (Media $\left.\pm D E\right)$} \\
\hline$L H \pm P H$ & Control & $p$-value & $L H \pm P H$ & Control & $p$-value \\
\hline $1,86 \times 10^{5} \pm 2,86 \times 10^{5}$ & $4,20 \times 10^{5} \pm 1,29 \times 10^{5}$ & 0,818 & $6,39 \times 10^{4} \pm 1,60 \times 10^{4}$ & $2,21 \times 10^{4} \pm 5,76 \times 10^{4}$ & 0,243 \\
\hline
\end{tabular}

Prueba de Mann-Whitney

\section{Proteína total, iones de calcio, fosfato y magnesio en SE y SNE}

Se observó que los niños con $\mathrm{LH} \pm \mathrm{PH}$ presentaron un leve aumento en los iones fosfato, calcio y proteína total, y una disminución en la concentración de magnesio tanto en SE como SNE. Sin 
embargo, solo se presentaron diferencias significativas en proteína total de SNE, evidenciando que la concentración de estas biomoléculas es superior en SNE de niños LH \pm PH (Tabla 5).

Tabla 5. Concentración de fosfato, calcio, magnesio y proteína total en SE y SNE de ambos grupos en estudio.

\begin{tabular}{lcccccc}
\hline \multirow{2}{*}{ Variable } & \multicolumn{3}{c}{ SE (Media $\pm D E$ ) } & \multicolumn{3}{c}{ SNE (Media $\pm D E)$} \\
\cline { 2 - 7 } & $\mathbf{L H} \pm \mathbf{P H}$ & Control & $\boldsymbol{p}$-value & LH $\pm \boldsymbol{P H}$ & Control & $\boldsymbol{p}$-value \\
\hline Fosfato $(\mathrm{nmol} / \mu \mathrm{L})$ & $0,14 \pm 0,05$ & $0,13 \pm 0,06$ & 0,163 & $0,26 \pm 0,11$ & $0,21 \pm 0,12$ & 0,053 \\
\hline Calcio $(\mathrm{nmol} / \mu \mathrm{L})$ & $0,42 \pm 0,27$ & $0,32 \pm 0,19$ & 0,324 & $0,47 \pm 0,24$ & $0,46 \pm 0,22$ & 0,969 \\
\hline Magnesio $(\mathrm{nmol} / \mu \mathrm{L})$ & $0,13 \pm 0,08$ & $0,14 \pm 0,04$ & 0,148 & $0,07 \pm 0,04$ & $0,09 \pm 1,05$ & 0,134 \\
\hline Proteína total $(\mathrm{mg} / \mathrm{mL})$ & $0,39 \pm 0,11$ & $0,35 \pm 0,11$ & 0,104 & $0,42 \pm 0,13$ & $0,29 \pm 0,12$ & $\mathbf{0 , 0 0 4 *}$ \\
\hline
\end{tabular}

${ }^{*} p<0,05$. Prueba de Mann-Whitney

\section{Discusión}

La comunicación constante entre las cavidades oral y nasal de pacientes con $\mathrm{LH} \pm \mathrm{PH}$, además de comprometer la alimentación y la respiración, puede alterar el ecosistema oral generando un entorno diferente en comparación con individuos normales. También se asume que esta diferencia craneofacial influye en la composición, la velocidad del flujo salival, la secreción sistémica de las glándulas salivales y puede alterar la microbiota oral en niños que presentan esta anomalía $(20,21)$. Por consiguiente, en este estudio se analizaron algunas características fisicoquímicas de la saliva, que incluyeron evaluación de la tasa de secreción, pH y capacidad amortiguadora de SE y SNE, así como la cuantificación de iones, proteína total y células viables de $E M$ en un grupo de niños con $\mathrm{LH} \pm \mathrm{PH}$ y un grupo de niños control.

La SNE proporciona una fuente de información útil sobre su contribución en la homeostasis oral debido a que se encuentra en reposo la mayor parte del día, y es considerada el principal determinante para el barrido oral confiriendo un fuerte efecto protector contra la caries, por ejemplo ${ }^{(22,23)}$. Por otro lado, la SE también cumple funciones protectoras, pero, aunque se encuentra en boca por menos tiempo, representa la secreción normal como respuesta a la ingesta de alimentos y a diversos estímulos mecánicos u olfativos, generando un aumento en la tasa de flujo y el pH salival, y un cambio en la composición de iones y concentración de proteínas secretadas ${ }^{(22)}$. Por lo tanto, se observó que el pH de la SE de los niños de ambos

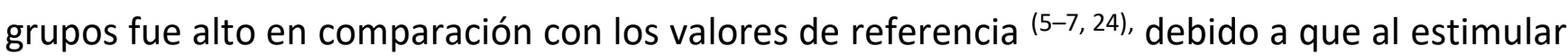
las glándulas salivales se secretan proteínas con capacidad buffer y se activa el sistema 
bicarbonato ${ }^{(12)}$, ocasionando un incremento en los niveles basales del pH durante el tiempo del estímulo. Sin embargo, a pesar de evidenciar que los valores del pH de SE y SNE de los niños con $\mathrm{LH} \pm \mathrm{PH}$ y control son superiores a 7,0 , se encontraron diferencias significativas; estos resultados no concuerdan con los reportados en otros estudios que indican que el $\mathrm{pH}$ de la saliva de niños con $\mathrm{LH} \pm \mathrm{PH}$ es igual al de los niños del grupo control ${ }^{(25,26)}$. Además de evidenciar un incremento en el $\mathrm{pH}$ de la $\mathrm{SE}$ de los niños con $\mathrm{LH} \pm \mathrm{PH}$ y control, fue posible determinar que la capacidad amortiguadora de la SE de los niños con $\mathrm{LH} \pm \mathrm{PH}$ es baja $(<5,5)^{(24)}$ en comparación con el grupo control, lo que podría indicar que la habilidad de la saliva de estos niños para contrarrestar los cabios de $\mathrm{pH}$ de cavidad oral es insuficiente.

La composición de la saliva varió de acuerdo con su tipo (estimulada o no estimulada) como respuesta a la función que cada una de ellas cumple ${ }^{(22,23)}$. Al comparar los grupos se evidenció que aunque la concentración de fosfato y calcio no fueron significativamente diferentes a las del grupo control, la SNE de los niños con LH \pm PH presentaron un aumento en los niveles de estos iones y una disminución en los niveles de magnesio. Este hallazgo está en concordancia con estudios realizados anteriormente en SNE ${ }^{(21,26,27) .}$

La concentración de proteína total en SNE fue mayor en niños con $\mathrm{LH} \pm \mathrm{PH}$; estos resultados concuerdan con los hallazgos de estudios recientes que reportan un incremento estadísticamente significativo en comparación con el grupo control ${ }^{(21,26)}$. Es importante mencionar que la saliva primaria, formada a nivel de los acinos, principalmente los serosos, aporta el contenido de proteínas a la saliva total, la cual es modificada a nivel de los conductos para ser finalmente secretada; además, las variaciones en los niveles de proteína total ocurren en respuesta a cambios fisiológicos o a diferentes estados patológicos ${ }^{(12,15,28)}$. Deshpande y colaboradores establecieron que existe correlación entre los niveles de proteína total en SNE en niños con defectos congénitos asociados a $\mathrm{LH} \pm \mathrm{PH}$, y establecen, por lo tanto, que la saliva puede ser utilizada como un biomarcador que puede ayudar a comprender la constitución genómica de defectos congénitos ${ }^{(28)}$. Además, se ha reportado que el incremento en los niveles de proteína total puede deberse a la sobre-expresión de varias proteínas secretadas (actina, cistatinas salivales, queratinas y otros activadores de queratinocitos) que son de vital importancia para la protección general y la regeneración tisular en pacientes con labio y paladar hendido ${ }^{(27,29)}$.

El aumento en la concentración de proteína total en SNE se podría explicar desde el punto de vista biológico y genético asociado a $\mathrm{LH} \pm \mathrm{PH}{ }^{(30)}$. Aunque en este estudio no se hizo una caracterización genética de los pacientes con $\mathrm{LH} \pm \mathrm{PH}$, ni se identificaron posibles genes 
asociados al defecto, estos resultados podrían sugerir la presencia de una alteración en la formación de las glándulas salivales, como por ejemplo atrofia de los acinos mucosos y obliteración de los conductos, lo cual explicaría además la disminución observada en el pH y la capacidad amortiguadora de la SNE. Esta especulación estaría en línea con lo reportado en recientes investigaciones en ratones con defectos genéticos asociados a $\mathrm{LH} \pm \mathrm{PH}$, en donde además de la hendidura, se presentaron alteraciones en la morfogénesis y función de las glándulas salivales, principalmente las submandibulares. Como consecuencia, la salud oral fue afectada debido a la disminución del flujo salival, capacidad buffer y al aumento de los niveles de Streptococcus mutans ${ }^{(16,20)}$. Además, como los pacientes con $\mathrm{LH} \pm \mathrm{PH}$ pueden presentar un espectro fenotípico, se esperaría que retengan alguna función de la proteína afectada. En consecuencia, sería razonable esperar interrupciones más sutiles en la función de la glándula salival ${ }^{(20)}$, tal como se evidencia en este estudio. De allí la importancia de realizar este tipo de investigaciones que proporcionen las bases para posteriores estudios de tipo genético que corroboren las hipótesis planteadas a partir de los resultados del orden fenotípico aquí encontrados.

Así mismo, como la saliva es el principal vehículo de movilización y transmisión de microorganismos, se optó por estimar los niveles de EM en este fluido. Estudios previos han señalado que los niveles de EM en saliva aumentan en pacientes con $\mathrm{LH} \pm \mathrm{PH}{ }^{(25,31)}$. De manera similar y pese a no encontrar diferencias significativas, se evidencio una mayor cantidad de células viables en SNE de pacientes con $\mathrm{LH} \pm \mathrm{PH}$ comparado con el grupo control. Ahluwalia y colaboradores determinaron que los niveles de EM de SNE de niños con $\mathrm{LH} \pm \mathrm{PH}$ fueron significativamente elevados, probablemente porque luego de consumir carbohidratos fermentables, presentaban un tiempo de aclaramiento oral más prolongado que los niños del

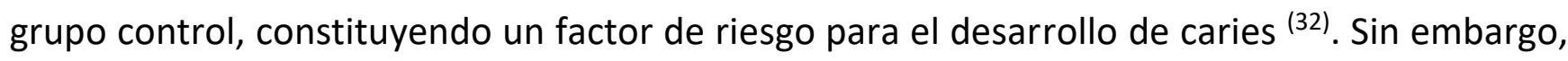
los resultados de este estudio podrían deberse a la disminución encontrada en el $\mathrm{pH}$ y capacidad amortiguadora en SNE de este grupo; lo que podría darle mayor susceptibilidad a la colonización bacteriana.

\section{Conclusiones}

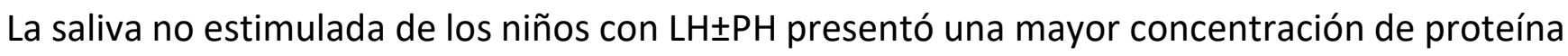
total y una disminución del pH y capacidad amortiguadora con respecto al grupo control; lo que podría predisponer a una menor habilidad para neutralizar ácidos y por lo tanto menor capacidad a la remineralización. Aunque, estas diferencias podrían explicarse desde el punto de vista biológico por una alteración en la formación y función de las glándulas submandibulares que más aportan a la secreción de SNE; deben realizarse estudios para 
corroborar esta hipótesis. Sin embargo, estos resultados podrían resaltar la importancia de evaluar la SNE en los programas de salud oral de pacientes con $\mathrm{LH} \pm \mathrm{PH}$.

\section{Agradecimientos}

Fundación Clínica Noel, Medellín, Colombia y sus pacientes por su participación en este estudio.

\section{Financiación}

IADR Colombia, Grupo de investigación EBSC.

\section{References}

1. Leslie EJ, Marazita ML. Genetics of cleft lip and cleft palate. Am J Med Genet C Semin Med Genet. 2013;163C(4):246-258.

2. República de Colombia. Instituto Nacional de Salud. Informe final del evento de vigilancia de anomalías congénitas. [Internet]. 2017. [Citado 2020 oct. 7]. Disponible en:

http://www.ins.gov.co/Paginas/busqueda.aspx?k=informe\%20de\%20evento\%20defe ctos\%20congenitos.

3. Jiang R, Bush JO, Lidral AC. Development of the upper lip: morphogenetic and molecular mechanisms. Dev Dyn. 2006;235(5):1152-66.

4. Gritli-Linde A. Molecular control of secondary palate development. Dev Biol. 2007;301(2):309-26.

5. Kohli SS, Kohli VS. A comprehensive review of the genetic basis of cleft lip and palate. J Oral Maxillofac Pathol. 2012;16(1):64-72.

6. Dixon MJ, Marazita ML, Beaty TH, Murray JC. Cleft lip and palate: understanding genetic and environmental influences. Nat Rev Genet. 2011;12(3):167-78.

7. Wehby $\mathrm{GL}$, Cassell $\mathrm{CH}$. The impact of orofacial clefts on quality of life and healthcare use and costs. Oral Dis. 2010;16(1):3-10.

8. Kondo S, Schutte BC, Richardson RJ et al. Mutations in IRF6 cause Van der woude and popliteal pterygium syndromes. Nat Genet. 2002;32(2):285-89. 
9. Jugessur A, Farlie PG, Kilpatrick. The genetics of isolated orofacial clefts: from genotypes to subphenotypes. Oral Dis. 2009;15(7):437-53.

10. Huang L, Jia Z, Shi $Y$ et al. Genetic factors define CPO and CLO subtypes of nonsyndromicorofacial cleft. PLoS Genet. 2019;15(10):e1008357.

11. Jayaraj D, Ganesan S. Salivary $\mathrm{pH}$ and buffering capacity as risk markers for early childhood caries: a clinical study. Int J Clin Pediatr Dent. 2015;8(3):167-71.

12. Amerongen AV. Veerman EC. Saliva-the defender of the oral cavity. Oral Dis. 2002;8(1):12-22.

13. Kaufman E, Lamster IB. The diagnostic applications of saliva-a review. Crit Rev Oral Biol Med. 2002;13(2):197-212.

14. Pedersen AM, Bardow A, Jensen SB, Nauntofte B. Saliva and gastrointestinal functions of taste, mastication, swallowing and digestion. Oral Dis. 2002;8(3):117-29.

15. Dawood IM, El-Samarrai SK. Saliva and Oral Health. Int J Adv Res Biol Sci. 2018;5(7):145.

16. Metwalli KA, Do MA, Nguyen $\mathrm{K}$ et al. Interferon Regulatory Factor 6 is necessary for salivary glands and pancreas development. J Dent Res. 2018;97(2):226-36.

17. Bretz WA, Do Valle EV, Jacobson JJ et al. Unstimulated salivary flow rates of young children. Oral Surg Oral Med Oral Pathol Oral Radiol Endod. 2001;91(5):541-5.

18. Grassia $\mathrm{V}$, Lombardi A, Kawasaki $\mathrm{H}$ et al. Salivary microRNAs as new molecular markers in cleft lip and palate: a new frontier in molecular medicine. Oncotarget. 2018;9(27):18929-38.

19. Ericsson Y, Hellström I, Jarkd B, Stjernström L. Investigations into the relationship between saliva and dental caries. Acta Odontol Scand. 1953;11(3-4):179-94. 
20. Tamasas B, Cox T, Herring S, Mclean JS, Kapadia H. Salivary gland and tooth abnormalities massively increase caries susceptibility in a mouse model of cleft lip/palate. J Dent Res. 2017;96(3):315-22.

21. Aizenbud D, Peri-Front Y, Nagler RM. Salivary analysis and antioxidants in cleft lip and palate children. Arch Oral Biol. 2008;53(6):517-22.

22. Sreebny LM. Saliva in health and disease: An appraisal and update. Int Dent J. 2000;50(3):140-61.

23. Tayab T, Rai K, Kumari AV. Evaluating the physicochemical properties and inorganic elements of saliva in caries-free and caries-active children. An in vivo study. Eur J Paediatr Dent. 2012;13(2):107-112.

24. Martínez-Pabón MC, Ramírez-Puerta BS, Escobar-Paucar GM, Franco-Cortés AM. Physicochemical salivary properties, lactobacillus, mutans streptococci counts and early childhood caries in preschool children of Colombia. Acta odontol latinoam. 2010;23(3):294-56.

25. Cheng LL, Moor SL, Kravchuk O, Meyers IA, Ho CT. Bacteria and salivary profile of adolescents with and without cleft lip and/or palate undergoing orthodontic treatment. Aust Dent J. 2007;52(4):315-21.

26. Almaeeni MM, Hassan AM. Selected salivary physicochemical properties among cleft lip and palate children in Iraq. Int J Med Res Heal Sci. 2018;7(9):132-36.

27. Szabo GT, Tihanyi $R$, Csulak $F$ et al. Comparative salivary proteomics of cleft palate patients. Cleft Palate Craniofac J. 2012;49(5):519-23.

28. Deshpande RR, Sabhloka S, Patila V et al. Comparative evaluation of salivary total protein levels in patients with cleft lip-palate to healthy children in mixed dentition age group. Dent J. 2015; 111:255-59.

29. Deshpande RR, Sabhlok S, WaknisShow P, Luniya P. Comparative evaluation of salivary total protein in cleft lip palate children to their mother and between healthy children to their mother. Res j pharm biol chem sci. 2014;6(5):386-90. 
30. Beaty TH, Marazita ML, Leslie EJ. Genetic factors influencing risk to orofacial clefts: today's challenges and tomorrow's opportunities. F1000Res. 2016;5:2800.

31. Sundell AL, Ullbro C, Marcusson A, Twetman S. Comparing caries risk profiles between 5 -and 10-year-old children with cleft lip and/or palate and non-cleft controls. BMC Oral Health. 2015;15(1):1-6.

32. Ahluwalia M, Brailsford SR, Tarelli E et al. Dental caries, oral hygiene, and oral clearance in children with craniofacial disorders. J Dent Res. 2004;83(2):175-9. 